HortSCIENCE 25(5):577. 1990.

\title{
Inhibition of Stratification and Germination of Apple Seeds by Paclobutrazol
}

\section{Finn Måge ${ }^{1}$ and Loyal Powell Department of Pomology, Cornell University, Ithaca, NY 14853}

Additional index words. growth regulator, growth inhibitor, Malus domestics

Seeds of apple (Malus domestics Borkh.) require stratification for normal germination. The chilling component of stratification may be associated with an increasing capacity for gibberellin (GA) biosynthesis as chilling proceeds (Powell, 1987). If true, then an inhibitor of GA biosynthesis might be expected to impede stratification. The object of our research was to determine if the efficiency of the stratification process in apple could be impeded by a GA inhibitor, as reported earlier for Corylus (Arias et al., 1976).

'Idared' apple seeds were removed from the fruits a few days after harvest in 1987 , air-dried, and stored at room temperature until needed. Intact seeds were stratified in mois sand in petri dishes at $6 \mathrm{C}$. At the end of the stratification period, the embryos were excised and germinated in light at $21 \pm 1 \mathrm{C}$ in petri dishes on filter paper moistened with an aqueous solution ( $0.1 \mathrm{~g} \cdot$ liter $\left.^{-1}\right)$ of the fungicide Captan. Observations were recorded every 2 days for 10 days, The number of days to $50 \%$ germination of the embryos in each petri dish was calculated on day 10 .

Preliminary experiments established $1 \times$ $10-{ }^{5}$ to $2.5 \times 10^{-5} \mathrm{M}$ paclobutrazol (PBZ) (Cultar, ICI Americas, Wilmington, Del.) as especially effective in inhibiting apple seed germination. The experimental unit was one petri dish containing 20 embryos in a completely randomized design. Replications consisted of two or four petri dishes. Percentage data were not transformed. Data were analyzed by linear regression and analysis of variance.

Paclobutrazol was inhibitory to germination when added during the stratification and/ or the germination phases (Table 1). Paclobutrazol added during the stratification process reduced germination by an additional $25 \%$

Received for publication 27 June 1988. The cost of publishing this. paper was defrayed in part by the payment of page charges. Under postal regulations, this paper therefore must be hereby marked advertisement solely to indicate this fact. 'Professor, Dept. of Horticulture, Agricultural Univ. of Norway, N-1432 AasNLH.

${ }^{2} 6.5$ weeks at $6 \mathrm{C}$. more than treatment during germination only and increased the time to 5070 germination by 2.7 days.

Since PBZ inhibits GA biosynthesis, the addition of GA should counteract the PBZ inhibition if, in fact, its inhibitory effect in apple seeds occurs via the GA system. This possibility was tested by adding $\mathrm{GA}_{3}(2.5 \times$ $\left.10^{-5} \mathrm{M}\right)$ during the germination stage. Gibberellic acid almost completely nullified the inhibitory action of PBZ, but only in wellstratified (5 weeks) seeds (Fig. 1). Seeds stratified for $<5$ weeks were not completely relieved of dormancy, as indicated by a longer days-to-germination value, and it was in those seeds that $\mathrm{GA}_{3}$ did not entirely relieve the inhibition from PBZ. Thus, there appears to be a component of the inhibition by PBZ that cannot be relieved by GA, at least not by $\mathrm{GA}_{3}$. PBZ is known to have effects on plants in addition to those directly involving GA (Dalziel and Lawrence, 1984), but our data do not support the view that PBZ affected a non-GA system.

These results indicate that PBZ inhibits apple seed processes at both the germination and stratification stages. Its inhibition can be partly to entirely overcome by $\mathrm{GA}_{3}$, depending on the amount of stratification received.

\section{Literature Cited}

Arias, I., P.M. Williams, and J.W. Bradbeer. 1976. Studies in seed dormancy. IX. The role of gibberellin biosynthesis and the release of bound gibberellins in the post-chilling accumulation of gibberellin in seeds of Corylus avellana L. Planta

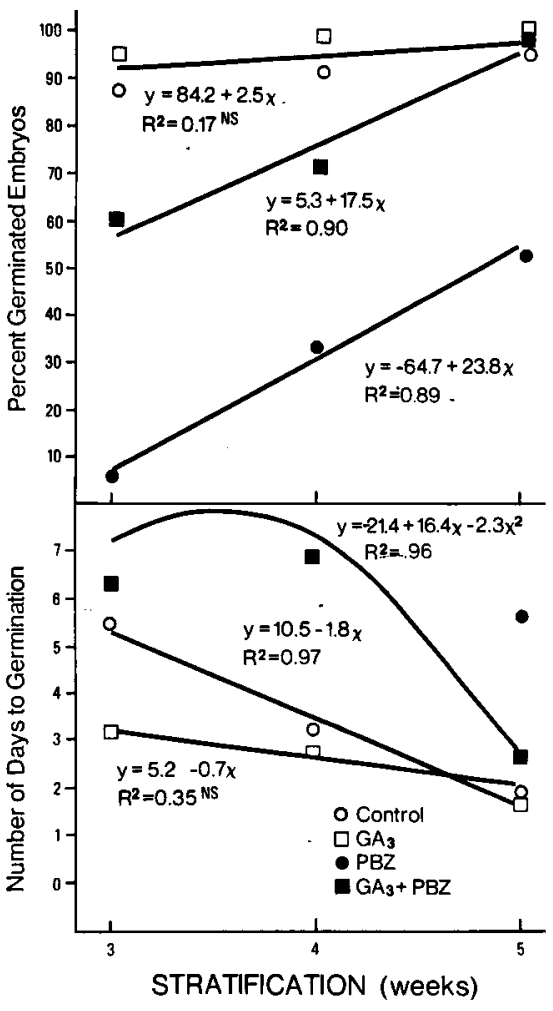

Fig. 1. Effect of $\mathrm{GA}_{3}$ and PBZ (both at $2.5 \times$ $10^{-5} \mathrm{M}$ ), added after stratification, on germination of 'Idared' embryos stratified for 3, 4, or 5 weeks at $6 \mathrm{C}$. Few embryos germinated when PBZ alone or combined with $\mathrm{GA}_{3}$ was used, and thus the number of days to germination could be calculated only for the longest stratification time. NS = not significant. All other relationships significant at $P=0.01$. Each point is the mean of two replicates.

131:135-139

Dalziel, J. and D.K. Lawrence. 1984. Biochemical and biological effects of kaurene oxidase inhibitors such as paclobutrazol, p. 43-57. In: R. Menhenet and D.K. Lawrence (eds.). Biochemical aspects of synthetic and naturally occurring plant growth regulators. British Plant Growth Group, Monogr. 11.

Powell, L.E. 1987. Hormonal aspects of bud dormancy in temperate-zone woody plants. HortScience 22:845-850.

Table 1. Germination of 'Idared' embryos as influenced by addition of paclobutrazol (PBZ) at the beginning of the stratification and/or the germination periods.

\begin{tabular}{lccc}
\hline \hline & PBZ $(\mathrm{M})$ & $\begin{array}{c}\text { Germination } \\
(\%)\end{array}$ & $\begin{array}{c}\text { Time to } 50 \% \\
\text { germination } \\
\text { (day) }\end{array}$ \\
\hline At stratification & At germination & 99 & 2.1 \\
\hline 0 & 0 & 64 & 4.1 \\
0 & $2.5 \times 10^{-5}$ & 39 & 6.8 \\
$2.5 \times 10^{-5}$ & $2.5 \times 10^{-5}$ & 20.7 & 1.09 \\
\hline LSD 0.05 & & &
\end{tabular}

${ }^{y}$ Each mean contained four observations. 